International Journal of Current Advanced Research

ISSN: O: 2319-6475, ISSN: P: 2319 - 6505, Impact Factor: SJIF: 5.995

Available Online at www.journalijcar.org

Volume 6; Issue 3; March 2017; Page No. 2872-2875

DOI: http://dx.doi.org/10.24327/ijcar.2017.2875.0129

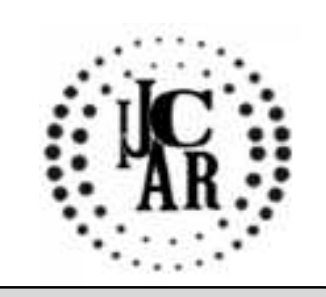

Research Article

\title{
A STUDY TO ASSESS THE AWARENESS OF NEEDLE PRICK INJURIES AMONG THE FIRST YEAR DIPLOMA NURSING STUDENTS AT A SELECTED MEDICAL CENTRE, MALAYSIA
}

\section{*Mini Rani Mary Beth and Kee Kaeh Ching}

Division of Nursing, International Medical University, 126, JalanJalil Perkasa 19, Bukit Jalil, 57000, Kuala Lumpur, Malaysia

\section{A R T I C L E I N F O}

\section{Article History:}

Received $15^{\text {th }}$ December, 2016

Received in revised form $24^{\text {th }}$ January, 2017

Accepted $14^{\text {th }}$ February, 2017

Published online $28^{\text {th }}$ March, 2017

Key words:

Awareness, needle prick injury, nursing students

\begin{abstract}
A B S T R A C T
Background: Needle prick injuries are common among the health care providers all over the world. Nursing students are no exception because they perform their clinical activities during the period of their study. Objective: The objective of this study is to assess the awareness of needle prick injuries among the first year nursing students at school of nursing in a selected Medical Center, Malaysia. Betty Neuman's systems model was used in this study as a theoretical framework. Methods and materials: A cross sectional descriptive design was used and the target populations were the first year diploma nursing students studying at the medical Center. Universal sampling technique was used to choose the participants in this study. There were 197 participants. Data was collected using selfdeveloped questionnaire and analysed using SPSS version 20. Results: The study results shows that most of the students $131(66.4 \%)$ have good knowledge and awareness about needle prick injuries, meanwhile 61 (30.9\%) have moderate knowledge and $5(2.5 \%)$ have poor knowledge. Conclusion: The study findings will give other nursing educational institutions some insight to improve the contents of teaching related to needle prick injuries in order to improve students' knowledge and awareness about needle prick injuries.
\end{abstract}

Copyright $@ 2017$ Mini Rani Mary Beth and Kee Kaeh Ching. This is an open access article distributed under the Creative Commons Attribution License, which permits unrestricted use, distribution, and reproduction in any medium, provided the original work is properly cited.

\section{INTRODUCTION}

According to World Health Organization (WHO), 35.7 million health care workers in the world are exposed to the risk of needle prick injuries. Recently over 20 million dedicated health care providers were exposed to biological, chemical and mechanical hazards daily. The World Health Organization estimates that approximately three million health care providers are exposed to blood and the body fluids due to needle or sharps injuries annually. Due to these exposures, approximately 1000 health care providers are estimated to suffer from serious infections annually. Center for Disease Control (CDC) estimates that around 600,000 to one million needle prick injuries cases occur every year. But unfortunately, about half of the needle prick injuries were not reported. [1] It is also reported that insufficient clinical experience and occupational safety training is provided by nursing schools and hospitals, hence nursing students are at high risk of needle prick injuries.[2]. The Health Unit of Ministry of Health, Malaysia, reported that the incidence rate of 4.7 needle prick injuries per 1,000 is among the health care workers in 2005. [3] According to Mohd Faid et al. (2005), the number of reported injuries among the health care workers in the Ministry of health, Malaysia from September 1997 to

*Corresponding author: Mini Rani Mary Beth

Division of Nursing, International Medical University, 126, JalanJalil Perkasa 19, Bukit Jalil,
December 1999 was a total of 556 cases and, among them total $403(72.5 \%)$ cases were caused by needle prick injuries. [4] A report by the Sabah State Health Department, Malaysia showed that the highest percentage $(74.5 \%)$ of needle prick injuries occurred among the staff nurses. [5]

Needle prick injuries among the health care providers are recognized as one of the occupational health hazard. It can cause a significant risk to the health care providers and threat to the medical and nursing students. It increases the risk of spreading disease such as HIV, Hepatitis B and Hepatitis C.[6]Needle prick injuries can be prevented and learning following incidents should be in place to avoid repeated accidents. [7] A study done by Santhna et al. (2007) showed that most frequent needle prick injuries occur among the staff nurses. Nearly $90 \%$ of them are emotionally upset and worried that they might contract with the disease. [8]

This study uses Betty Nueman's systems model. This model identifies the nursing students as the central core surrounded by three types of defense mechanisms which are flexible line of defense, normal line of defense, and line of resistance. [9]

\section{Objective}

The objective of this study is to assess the awareness of needle prick injuries among the first year diploma nursing students at the school of nursing in a selected Medical Center, Malaysia. 


\section{METHODS AND MATERIALS}

A cross sectional and descriptive design was used to study the awareness and awareness on needle prick injuries among the first year nursing students at school of Nursing in a selected medical Centre. The target population is the first year diploma nursing students studying at the school of nursing in a Medical Center. Universal sampling technique was used to choose the participants in this study. All the first year diploma nursing students in the school of Nursing were chosen as samples. The participants who meet the inclusion criteria were chosen for the study.

\section{Inclusion criteria}

- First year nursing students in the school of Nursing

- Willing to participate in the study.

- Able to understand English and Bahasa.

- Students not exposed to any teaching on universal precaution.

\section{Exclusion criteria}

- Students from other courses.

- Students who are absent during the data collection.

- Nursing students from second year and third year of study.

- Students already taught about universal precaution.

A self-developed questionnaire is used in this study. The instrument consists of part A and B. Part A is the demographic data which consists of gender, age, religion and educational status. Part $\mathrm{B}$ is the questionnaire on knowledge and awareness of needle prick injuries. The B contains a total of 20 questions about knowledge and awareness of needle prick injuries. Each correct answer was given 1 point and each wrong answer and unsure responses were given 0 points. The findings were categorized as Good knowledge (16-20), Moderate knowledge (11-15) and Poor knowledge (below 10). The pilot study was conducted to determine the reliability of the questionnaire. The Cronbach Alpha coefficient for the questionnaire was 0.896 . Validity of the questionnaire was done by the panel of experts in the nursing college.

The research was approved by the International Medical University (IMU) Joint Committee of the Research and Ethical Committee. Written permission was obtained from the principal of the nursing college to conduct the study. Written consents were obtained from all participants. Confidentiality and anonymity was maintained. Privacy of the participants was ensured and participants were given the right to withdraw from this study. Data was analysed by Statistical Package for Social Science Software (SPSS) version 20. Descriptive statistics was used to analyse the demographic data of the participants and presented in frequency and percentage. The results were then presented in the form of tables and figures.

\section{RESULTS}

The demographic data of the participants are shown in Table 1. Most of the participants were female students $173(87.8 \%)$. The highest number of participants 186 (94.4\%) belonged to the age group between 16-20 years. A majority of the participants $186(94.4 \%)$ were Muslims. Most of them 150 (76.1\%) had SPM educational level.
Table 1 Demographic data of the participants $(n=197)$

\begin{tabular}{ccc}
\hline Demographic Data & n & \% \\
\hline Sex & & \\
Male & 24 & 12.2 \\
Female & 173 & 87.8 \\
Age (in years) & & \\
$16-20$ & 186 & 94.4 \\
$21-25$ & 11 & 5.6 \\
Religion & & \\
Islam & 186 & 94.4 \\
Buddhist & 2 & 1 \\
Christian & 4 & 2 \\
Hindu & 5 & 2.5 \\
Educational level & & \\
SPM & 150 & 76.1 \\
STPM & 2 & 1 \\
Diploma & 43 & 21.8 \\
Degree & 2 & 1 \\
\hline
\end{tabular}

The finding of the study shows that the entire student nurses $197(100 \%)$ knew that needle prick injuries are wounds caused by needles that accidentally puncture the skin. There were 157 $(79.7 \%)$ of them who knew that needle prick injuries are very common in the health care environment. However, 26 $(13.2 \%)$ of respondents were unsure that needle prick injuries are very common in health care field. A total of $85(43.1 \%)$ respondents did not know that most of the needle prick injuries have been neglected and reported and 66 (33.5\%) of the respondents were unsure. Only 46 (23.4\%) of the respondents knew that most of the needle prick injuries have been neglected and unreported. The respondents who knew that needle prick injuries are an occupational hazard in the medical community were $131(66.5 \%)$.

The results also shows that a total of $181(91.9 \%)$ respondents were aware that many pathogens are transmitted by needle prick injuries. However, 7 (3.6\%) of the respondents did not know that the pathogens are transmitted by needle prick injuries and $9(4.6 \%)$ of the respondents were unsure about this. A total of $191(97 \%)$ of the respondents were aware that after a needle prick injury the affected area should be rinsed and washed thoroughly with water and $170(86.3 \%)$ of them knew that the incidence of needle prick injury may lead to significant stress and anxiety for the affected injured person.

A total of $155(78 \%)$ respondents were aware that needle prick injuries results in blood borne diseases through the passage of Hepatitis B, C and HIV viruses. But, 5 (2.5\%) of the respondents were not aware about this. Moreover, 37 $(18.8 \%)$ of the respondents were not aware of the pathophysiology of the transmission. A majority of the participants $171(86.8 \%)$ were aware that most reported needle prick injuries involves nursing and laboratory staff. The respondents who were unsure on when Post-exposure Prophylaxis (PEP) should be initiated are 133 (67.5\%). The results also shows that $165(83.8 \%)$ of them were aware that most of the needle prick injuries occurred during disposal of used needle. However, $17(8.6 \%)$ were not aware of this and $15(7.6 \%)$ of them are unsure of the answer. About 190 $(96.4 \%)$ of the participants were aware that most of the needle prick injuries occur when recapping the used needle whereas half of them $108(54.8 \%)$ are still unclear about the sharp disposal.

A total of $144(73.1 \%)$ participants answered correctly by responding that needle after use should not be re-sheathed and only $80(40.6 \%)$ of them knew that the open skin areas or 
lesions on the hands and arms should be covered with dry dressing all the times. About 163 (82.7\%) participants answered correctly and disagreed to recap the used syringes before disposal.

Figure 1 shows the response to the question by the participants on 'Most needle prick injuries occur due to improper usage of personal protection equipment (PPE) and Reporting after needle prick injury is not useful'. There were $94(47.7 \%)$ respondents who are aware that most needle prick injuries occur due to improper usage of personal protection equipment (PPE).

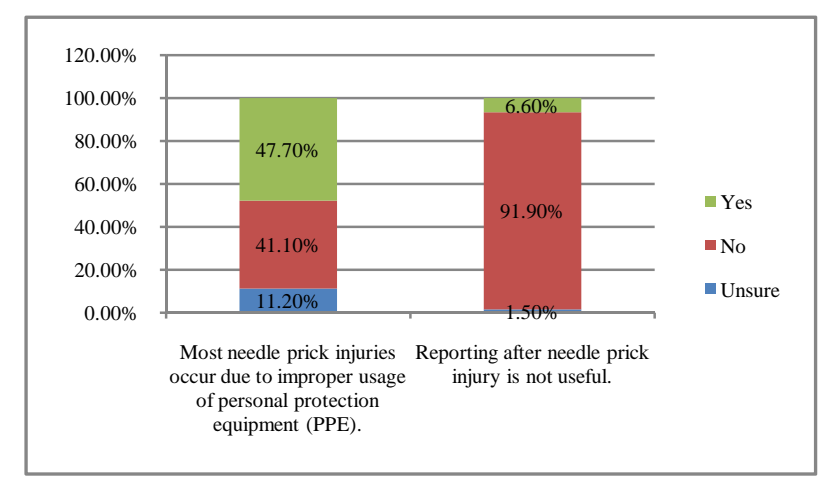

Figure 1 Response to the question by the participants 'Most needle prick injuries occur due to improper usage of personal protection equipment (PPE) and Reporting after needle prick injury is not useful'.

Figure 2 shows the student nurses level of knowledge and awareness about needle prick injuries. Most of the student nurses $131(66.4 \%)$ had good knowledge and awareness about needle prick injuries, and $61(30.9 \%)$ of them hadmoderate knowledgeand5 (2.5\%) had poor knowledge.

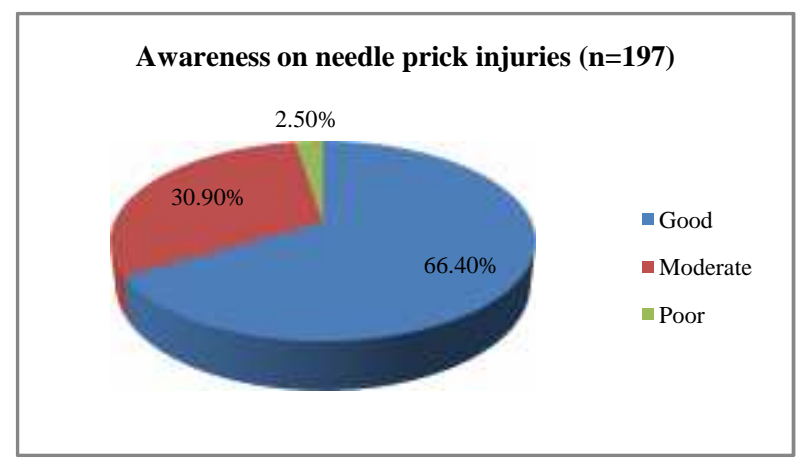

Figure 2 Awareness on needle prick injuries of the participants

\section{DISCUSSION}

The result of this study shows that 131 (66.4\%) nursing students have good knowledge and awareness regarding needle prick injuries.According to Lukianskyte et al. (2011), there is a need for the student nurses to have more effective training programs to reduce the incidence of needle prick injuries. [10] Needle prick injuries incidence can be prevented and reduced by over $80 \%$ with the use of safe needle devices, over $90 \%$ of injuries can be reduced in conjunction with worker education and work practice controls. [11]

The findings of this study also shows that $43.1 \%$ of the student nurses did not know that needle prick injuries have been neglected and unreported. The most common reasons for nursing students' failure to report the incidents of needle prick injuries are due to fear of stigmatization and discrimination and fear of the consequences of the injuries.[12] From this study findings, it is clear that the student nurses (83.8\%) are aware that needle prick injuries occurred during disposal of used needle. Centre of Disease Control states that needle prick injuries occur during sharp disposal. On the other hand, it is also found that $6.1 \%$ of the student nurses do not know that the needle prick injuries are an occupational hazard in the medical community in this study. [13] According to Wang et al (2003), needle stick injuries are a common event in the healthcare environment. [14]

However, a total of $91.9 \%$ the participants were aware that many pathogens are transmitted by needle prick injuries. Hence, more emphasis during teaching sessions can be given to the students regarding the pathogens that are transmitted by needle prick injuries to prevent further incidences.

\section{CONCLUSION}

Preventing needle prick injuries is the most effective way to protect health care workers and students nurses.Preventing needle prick injuries is an essential part of any blood borne pathogen prevention program in the workplace. Every health facility should have an infection control program at the working place through the hospital infection control committee. The World Health Organization (WHO) defines that "a safe injection" as one that does not harm to the recipient, does not expose the provider to any risks and does not cause any waste that are harmful to the society. [13] Knowledge and awareness on when Post-exposure Prophylaxis (PEP) should be initiated and its importance must also be emphasised to the students during their clinical practice. Overall, a total $66.4 \%$ of the student nurses have good knowledge and awareness about needle prick injuries. Not only health care workers are frequently exposed to the percutaneous injuries with contaminated sharps which cause infection, but also the student nurses. If appropriate precautions are not taken while clinical practice of students, there is high risk of contracting blood borne diseases.

Hospitals can prevent or reduce the occurrence of the injuries by establishing a better working environment in the terms of staffing and sufficient resources reduce the emotional exhaustion and retain more experienced nurses. [15] By reducing the occurrence of needle prick injuries, patients will also receive better nursing care.

\section{Acknowledgement}

The researchers express their deepest gratitude to the Head of Nursing Division, International Medical University (IMU), Associate Dean of IMU Research Laboratory, and Deputy CoChairman, IMU Joint-Committee on Research and Ethics for reviewing the research proposal and approving the research fund. The researchers are deeply indebted to the Principal, college of Nursing for granting permission to conduct pilot study and data collection, respectively.

\section{References}

1. Lee, L. K., \& Hassim, I. N. (2005). Implication of the prevalence of needlestick injuries in a General Hospital in Malaysia and its risk in clinical practice. Environmental health and preventive medicine, 10, 3341.

2. Yao, W. X., Yang, B., Yao, C., Bai, P. S., Qian, Y. R., Huang, C. H. \& et al. (2010). Needlestick injuries 
among nursing students in China. Nurse Education Today, 30(5), 435-437.

3. Bhardwaj, A., Sivapathasundaram, N., Mf, Y., \& Ah, M. (2014). The Prevalence of Accidental Needle Stick Injury and their Reporting among Healthcare Workers in Orthopaedic Wards in General Hospital Melaka , Malaysia, Malaysia orthopaedic journal,8(2), 6-13.

4. Mohd Faid, A. R., Zainudin, M. A., Yusmah, M., Norizah, M., \& Rosnah, I. (2005).Neelde stick injuries among health care workers in Negeri Sembilan. Malaysian journal of public health medicine, 5(2), 1014.

5. Cheah, W. L., Giloi, N., Chang, C. T., \& Lim, J. F. (2012). The perception, level of safety satisfaction and safety feedback on occupational safety and health management among Hospital staff nurses in Sabah state health department. Malays J Med Sci, 19(3), 5763.

6. Gyanchand Rampal, Lekhraj Rampal and Zakaria, Rosidah and Leong, Whye Sook and Md. Zain, Azhar (2010) Needle stick and sharps injuries and factors associated among health care workers in a Malaysian hospital. European Journal of Social Sciences, 13 (3). pp. 354-362.

7. Royal College of Nursing (2013). Sharps safety, RCN guidance to support the implemnetaiton of the health and safety (Sharp instruments in health care regulations).
8. Santhna, L.P., Samsiah, M., Raja Lexshimi, RG., Roshdinom, R., Ho, S.E., \& Hamidah, H. (2007). Sharp injury in Hospital Universiti Kebangsaan Malaysia (HUKM): Experiences of health care workers and students. Med \& health, 2(1), 86-92.

9. Pearson, A., Vaughan, B., \& FitzGerald, M. (2005) Nursing models for practice. Third edition.Elsevier.

10. Lukianskyte, R., Gataeva, J., \& Radziunaite, L. (2011). Needle sticks and sharp injuries experienced by staff nurses and nursing students and their prevention. International journal of infection control, 3- 9.

11. American Nurses Association. (2002). Needle stick prevention guide.

12. Zungu, L. I., Sengane, M. L., \&Setswe, K. G. (2008). Knowledge and experiences of needle prick injuries (NPI) among nursing studnets at the university in Guateng, South Africa. Human Science Research Council, 50 (5), 48- 48c.

13. Waqar, S. H., Siraj, M., Razzaq, Z., Malik, Z. I. \&Zahid, M. A. (2011). Knowledge, attitude and practices about needle stick injuries in healthcare workers. Pak J Med Res. Vol. 50, No. 3.

14. Wang, H., Fennie, K., He, G., Burgess, J., \& Williams, A. B. (2003). A training programme for prevention of occupational exposure to bloodborne pathogens: impact on knowledge, behavior and incidence of needle stick injuries among the student nurses in Changsha, People's Republic of China. Journal of advanced nursing, 41(2), 187- 194.

15. Cho, E., Lee, H., Choi, M., Park, S. H., Yoo, I. Y., \& Aiken, L. H. (2014). Factors associated withneedlestick and sharp injuries among hospital nurses: A crosssectional questionnaire survey. International Journal of Nursing Studies, 50(8), 1025-1032.

\section{How to cite this article:}

Mini Rani Mary Beth and Kee Kaeh Ching (2017) 'A Study To Assess The Awareness Of Needle Prick Injuries Among The First Year Diploma Nursing Students At A Selected Medical Centre, Malaysia', International Journal of Current Advanced Research, 06(03), pp. 2872-2875.

DOI: http://dx.doi.org/10.24327/ijcar.2017.2875.0129 